Available online at: https://proceeding.researchsynergypress.com/index.php/rsfconferenceseries1

RSF Conference Series: Business, Management and Social Sciences

e-ISSN 2807-5803/ p-ISSN 2807-6699

Volume 1 Number 3 (2021): 1-8

\title{
Generation X Consumption Behavior Model in Using Digital Transactions
}

\author{
Afni Sirait1, Ida Ayu Purnama1 \\ ${ }^{1}$ National Development University "Veteran" Yogyakarta
}

\begin{abstract}
Technology is a necessity that cannot be separated from life today. Daily activities are made easier and even dismiss distance, space, and time. This convenience provides cost savings, increases time use quality, and even changes a business process. This study aims to analyze the model of consumer behavior of generation $\mathrm{X}$ in the use of digital transactions. This research is a quantitative approach with 73 respondents who fit the qualifications. The data was collected using a questionnaire which was then tested for validity, reliability, and model fit using the WarpPLS 6.0 analysis tool. The test results explained that consumption behavior mediated cultural factors do not directly affect the generation of digital transaction $\mathrm{X}$ (the value path coefficient $\mathrm{H} 1$ equals $-0007 \mathrm{P}=0,28$ ). Psychological factors have a direct influence on digital transactions Generation X (H2 has a value of path coefficients 0,12 and $\mathrm{P}=0,15$ ), but it has indirect influence the results of the mediation of the variable consumption behavior against the decision transaction generation digital $\mathrm{X}$ (the value path coefficient $0.728, \mathrm{P}<0.001$, and R-Squared 0.57 ) with the model fit testing the VIF value of 1.236 , and the GoF value of 0.411 . The limitation of this study is that the population only focuses on generation $\mathrm{X}$.
\end{abstract}

Keywords: Generation X, Psychology, Culture, Consumer Behavior, Digital Transaction

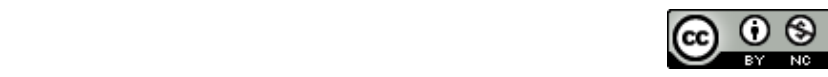

This is an open access article under the CC-BY-NC license

\section{INTRODUCTION}

Dependence on technology is one of the opportunities that are widely used by technology-based companies. Fulfillment of needs ranging from finding, getting, to paying using technology. This massive change affects many lifestyles and behavior of many people. Virtual payments are starting to appear. ALSaji (2019) explained that the banking industry currently provides technology-based facilities as a form of innovation and innovation process to save costs and increase efficiency.

Banks and financial institutions have finally created several facilities that can use customers to transact virtually. There are types of mobile banking, internet banking, SMS banking, and other virtual types. This regulation regarding electronic transactions is regulated by the Financial Services Authority (2017). Changes in culture and social environment such as accelerating the transformation of these changes. The transformation of technology-based and virtual or online transactions continues until finally, the types of appear e-money. The development of e-money is regulated by Bank Indonesia (2014). This ease of payment reduces the use of cash to become cashless.

This very turbulent use is not a surprising thing for generations with categories of gen $\mathrm{Y}$ and gen $\mathrm{Z}$. People born around 1981 until now are a generation that is very close to technology. Putra (2016) explained that generations $\mathrm{Y}$ and $\mathrm{Z}$ are a generation that relies heavily on technology. Especially Generation Z's mastery of information and technology is fundamental because they were born with very broad data access.

Corresponding author

Afni Sirait, afni.sirait@upnyk.ac.id

DOI: https://doi.org/10.31098/bmss.v1i3.281

Research Synergy Foundation 
Stevens (2019) explains that service and problem solving from customer banking will vary due to different generations of customers. The baby boomers generation is the pioneer generation in the transformation of the use of technology but still likes to complete transactions by meeting face-to-face. Generation X is a generation that likes convenience, makes transactions electronically, and most of them already use smartphones. Changes in habits in the use of technology are a condition experienced by generation $\mathrm{X}$ as a result of the first generation experiencing a transition period. This generation has experienced a lot of culture shock over this condition, so many are found who are still very lacking in updating the use of technology. Based on the things mentioned above, this study aims to examine the influence of cultural and psychological factors on digital transactions mediated by the consumption behavior of generation $\mathrm{X}$.

\section{LITERATURE REVIEW}

Kasasa (2021) explains the things that distinguish the characteristics between generations, such as media consumption, banking habits, shaping events, and financial horizon. Sipayo (2017) describes the intergenerational scheme into four categories based on generation theory, namely generation baby boomer (1945-1960), generation X (1961-1980), generation Y (19981-1995), and generation Z (after 1995). This generational difference greatly affects the way of behaving, especially in the work environment.

Khaniwale (2015) explained that consumer behavior is influenced by internal and external factors. External factors include cultural and social factors, while internal factors include personal and psychological factors. Each of these internal and external factors has its derivative factors. Other factors that influence changes in consumer behavior such as shopping experience, dynamics of price changes, personal interests, buying strategies, perceptions of price fairness, intention to satisfy themselves, etc. (Victor, Thoppan, Nathan, \& Maria, 2018).

Nilekani et al. (2019) define that digital transactions are payments made using a system without using cash and using digital modes or electronic media to send and receive money. Deloite (2014) describes the digital transaction ecosystem that has been adopted and forms an end-client ecosystem. The actors in this ecosystem are business people, government, and end consumers. Group (2018) describes several key trends affecting payments globally, namely increasing competition, the need for real-time payment, regulation and efficiency, and the importance of security.

Combi (2016) explains that changes in the use of technology do not necessarily occur because of the technology but because of many factors that encourage the use of technology, such as anthropology, culture, social change, and other sciences. Swain et al. (2020) and Hartl \& Hess (2017) explain that culture is a flexible and detailed thing to transform digital transactions. Saragih \& Nopriadi (2019) results of research state that culture significantly influences the use of technology to conduct transactions and payments online.

H1: Cultural factors have a significant effect on the use of digital transactions mediated by consumption behavior

Lin, Wang, \& Hung (2020) describe several psychological factors that influence a person to conduct digital-based transactions. Psychological factors such as personal risk, trust, and satisfaction. (Gia-Shie Liu \& Pham Tan Tai, 2016) added another psychological factor that influences the use of digital-based transactions. Mobility, convenience, suitability, knowledge, trust, risk, ease to use, multifunctional, and safe to use are things that will affect personal use. 
H2: Psychological factors have a significant effect on the use of digital transactions mediated by consumption behavior

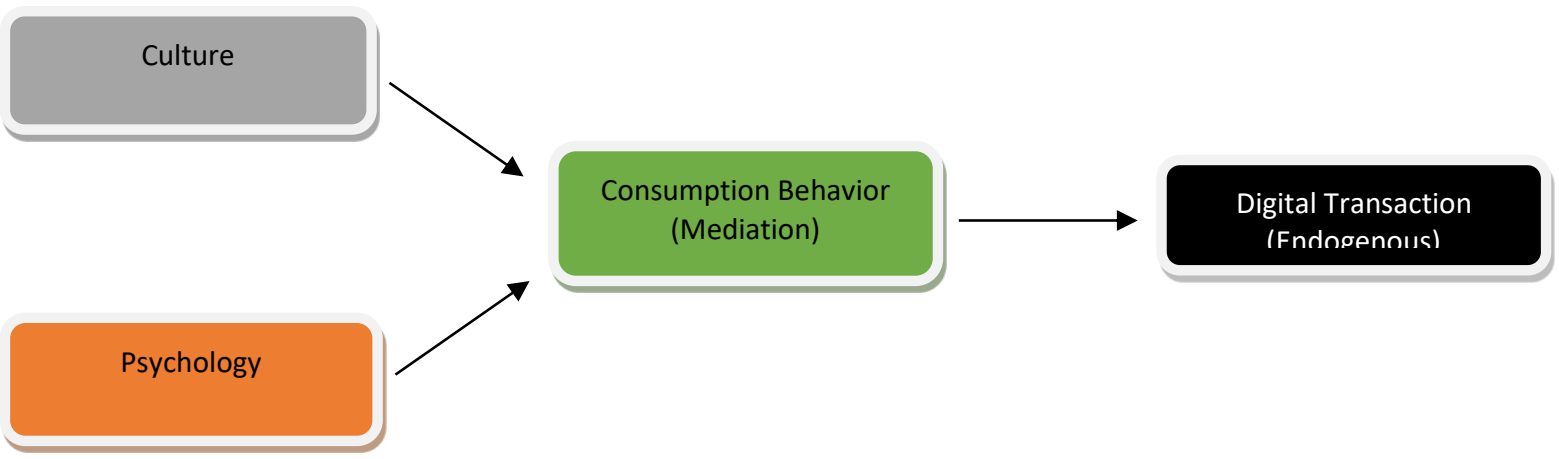

Figure 1. Hypothesis Framework

\section{RESEARCH METHOD}

This research will use quantitative research methods using a questionnaire as a data collection tool. Apuke (2017) mentions that quantitative research aims to test hypotheses and see the cause and effect of the predictions of the hypotheses built. Data analysis will be carried out using the Path Analysis method. This method is used to identify direct and indirect, significant and insignificant relationships of each variable that is built.

Data analysis will be carried out using endogenous, exogenous, and mediating variables. The endogenous variables are digital transactions, the exogenous variables are culture and psychology, while the mediating variable is the consumption behavior of generation $\mathrm{X}$. The mediation variable is used to analyze the paths of each indicator used and obtain the results of direct and indirect effects of endogenous and exogenous variables. Carrión et al. (2017) explained that the influence exerted by mediating variables could mediate fully, partially, and even not mediate. The variable assessment indicator in this questionnaire uses a Likert scale of 1-7. Cultural variables are arranged with six statements, psychological variables are arranged with six statements, consumption behavior variables are arranged with five statements, and digital transactions are arranged with five statements.

Initial testing is done by evaluating the measurement model to determine the reliability and validity of the construct. Test validity (test loading factor and AVE value) and reliability (calculate composite reliability and Cronbach's alpha). Then, the structure of the model was tested using analysis R-Square, Path Coefficients, T-statistics, Predicted Relevance, and Model Fit. The sample of this research is generation X, who was born around 1960 - 1980, with a total of 100 respondents. Sampling using purposive sampling method with respondent criteria as follows:

1. Using one of the banking facilities such as mobile banking, SMS banking, or internet banking for at least two years.

2. Using one of the electronic money such as Gopay, Ovo, Link Aja, Dana, Shoppepay, and other electronic money for transactions with accumulated transactions of at least 25 times in a minimum period of 12 months.

3. Perform online purchase transactions on one of the platforms at least five transactions within six months. 


\section{FINDINGS AND DISCUSSION}

Distribution was given to 100 respondents, and 73 respondents were selected who met the criteria of purposive sampling. The selected respondents consisted of 26 men and 47 women with various characteristics of age, domicile, and occupation. Descriptive data on banking account ownership explains that most of the respondents have two banking accounts (28.77\%) for activities to fulfill daily needs. Followed by three banking accounts, four banking accounts, one banking account, five banking accounts; some even have more than five banking accounts.

Respondents use digital transactions in the form of digital facilities from banking and use e-money to make online purchases. The frequency of online purchases within 12 months was made more than 30 times by 42 respondents, while the other 31 respondents made online purchases 21-30 times. This online learning is carried out at least once a week by 32 respondents, more than four times a week by 19 respondents, two times a week by 14 respondents, more than four times a week by four respondents, and some respondents shop as needed four times.

Validity testing is done by testing the loading factor of each indicator used to measure the variables used. The loading factor owned must be greater than 0.70 . The results of the validity test for the exogenous variable of consumption behavior (PK) show that the two indicators in the variable cannot be used as indicators of variable assessment (PK4 and PK5) because the test value is smaller than 0.70 . The two indicators have P-Value values of 0.492 and 0.034 , while the standard P-Value that must be owned by each indicator is $\mathrm{P}<0.005$ and an AVE value of at least 0.50 . Furthermore, reliability testing is carried out by testing composite reliability and Cronbach's Alpha with a value that must be greater than 0.70 . The data for testing the validity and reliability are presented in the following table.

Table 1. Composite Reliability Coefficient, Cronbach's Alpha, and AVE Value

\begin{tabular}{|l|c|c|c|}
\hline & $\begin{array}{c}\text { Cronbach's } \\
\text { Alpha }\end{array}$ & Composite Reliability & $\begin{array}{c}\text { Average Variance } \\
\text { Extracted (AVE) }\end{array}$ \\
\hline Culture $\left(\mathrm{X}_{1}\right)$ & 0.911 & 0.932 & 0.695 \\
\hline Psychology $\left(\mathrm{X}_{2}\right)$ & 0.967 & 0.973 & 0.858 \\
\hline Consumption Behavior (M) & 0.950 & 0.968 & 0.909 \\
\hline Digital Transactions (Y) & 0.880 & 0.913 & 0.677 \\
\hline
\end{tabular}

Source: Processed Data

Validity testing is done by test the discriminant validity with a standard value greater than 0.70 . The results of this test are shown in the output correlations among latent variables, which are presented in the following table.

Table 2. Output Correlations Among Latent Variables

\begin{tabular}{|l|c|l|l|r|}
\hline & PBT & PK & FB & FP \\
\hline Digital Transactions (PBT) & $\mathbf{( 0 . 8 2 3 )}$ & 0.742 & 0.127 & 0.147 \\
\hline
\end{tabular}


RSF Conference Series: Business, Management and Social Sciences, Vol. 1 (3), 1-8

Generation X Consumption Behavior Model in Using Digital Transactions

Afni Sirait, Ida Ayu Purnama

\begin{tabular}{|l|l|l|l|l|}
\hline Consumption Behavior (PK) & 0.742 & $\mathbf{( 0 . 9 5 3 )}$ & -0.041 & -0.034 \\
\hline Culture (FB) & 0.127 & -0.0410 .834 & $\mathbf{0}$ & 0.920 \\
\hline Psychology (FP) & 0.147 & -0.034 & 0.920 & $\mathbf{( 0 . 9 2 6 )}$ \\
\hline
\end{tabular}

Source: Processed Data

The next testing process is path analysis testing based on the structure of the research model that was formed at the beginning. The results of testing the model structure are presented in the image below.

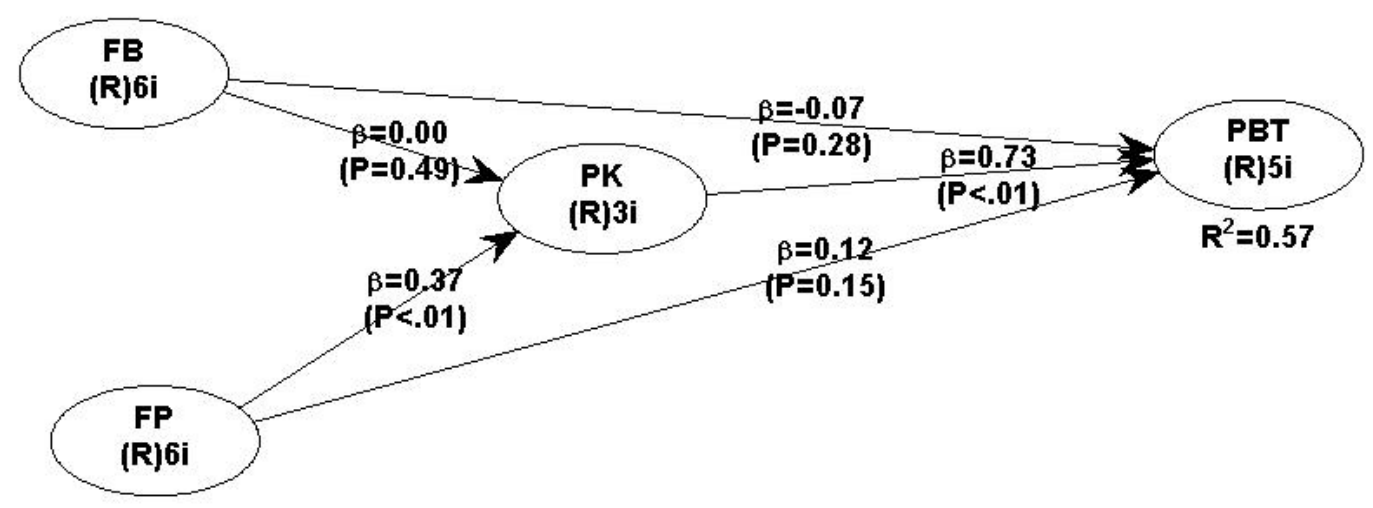

Figure 2. Structure Model Processing

The test results of the model structure presented in Figure 2 obtain a value model fit with an APC value of 0.256 or equal to $25.60 \%$ and P-value $=0.005$, ARS of 0.218 or equivalent to $21.80 \%$, and P-value $=0.012$. The calculation of the VIF value is 1,236 , and the GoF value is 0.411. Path coefficient value H1 equals $-0007 \mathrm{P}=0: 28$, while the $\mathrm{H} 2$ has a coefficient lines $\mathrm{P}=0: 12$ and $0: 15$. The overall path coefficient value is 0.73 with $\mathrm{P}<0.001$ and $\mathrm{R}$-Squared 0.57 .

Based on the results of data processing that have been presented above, further discussion of the research results will be carried out. This discussion will begin by presenting a summary of the hypotheses presented below.

Table 3. Direct and Indirect Effect

\begin{tabular}{|l|l|l|l|l|}
\hline \multicolumn{2}{|l|}{ Direct Effect } & \multicolumn{2}{l|}{ Indirect Effect } \\
\cline { 2 - 5 } & Path Coefficient & P-Value & Path Coefficient & P-Value \\
\hline FB-PBT & -0.065 & $\mathrm{P}=0.284$ & 0.002 & $\mathrm{P}=0.489$ \\
\hline FP-PBT & 0.116 & $\mathrm{P}=0.152$ & 0.268 & $\mathrm{P}<0.001$ \\
\hline
\end{tabular}


RSF Conference Series: Business, Management and Social Sciences, Vol. 1 (3), 1-8

Generation X Consumption Behavior Model in Using Digital Transactions Afni Sirait, Ida Ayu Purnama

\begin{tabular}{|l|l|l|l|l|}
\hline FB-PK & 0.003 & $\mathrm{P}=0.489$ & & \\
\hline FP-PK & 0.367 & $\mathrm{P}<0.001$ & & \\
\hline PK-PBT & 0.729 & $\mathrm{P}<0.001$ & & \\
\hline
\end{tabular}

Source: Processed Data

Testing H1 in Table 3 shows that the p-value (0.284) greater than the level of significance was set. $\mathrm{H} 1$ is not supported. $\mathrm{H} 1$ explains that cultural factors do not affect generation $\mathrm{X}$ in digital transactions. Testing H2 direct influence shows that the p-value (0152) is greater than the significant set, while the indirect linkage FP-PK showed a p-value $(<0.001)$ and PK-PBT shows the p-value $(<0.001)$. This relationship shows full mediation, then $\mathrm{H} 2$ supported.

Moqbel, Guduru, \& Harun (2020) explained that the test using the method path-analysis analysis gave real results about the relationship between endogenous and exogenous variables. The first hypothesis is that cultural factors in generation $\mathrm{X}$ do not have a direct and significant relationship to digital transactions even when mediated by factors of consumption behavior. The second hypothesis is that the psychological factor of generation $\mathrm{X}$ does not have a direct and significant relationship to digital transactions. However, the mediating variable, namely the consumption behavior factor, influences so that an indirect and significant influence appears so that it fully mediates. The results of this test support the research objective to examine the factors that influence generation $\mathrm{X}$ in conducting digital transactions, especially in the transactions. New normal. Current

\section{CONCLUSION}

Data collection, testing, and data analysis carried out concluded that cultural factors were not the main factor for Generation X to carry digital transactions even though they are mediated by consumer behavior. Psychological factors mediated by consumption behavior, in fact, influence Generation X to conduct digital transactions. Consumption behavior factors regarding shopping experiences, price changes, desire to buy, promotions, shopping habits, and other factors become things that mediate digital transactions.

The limitations of this study are the sample and population used only in generation X. Future research can expand the sample and population in a wider generation hierarchy to obtain a model that affects digital transactions between generations. Further research can also add richer exogenous variables to obtain broader knowledge development.

\section{ACKNOWLEDGMENT}

The authors would like to thank the Institute for Research and Community Service at Universitas Pembangunan Nasional Veteran Yogyakarta, Indonesia, for providing funds for this research.

\section{REFERENCES}

AL-Saji, D. A. (2019). The Role of Electronic Payment Methods in Facilitating Money Transactions in Erbil City. Cihan University-Erbil Journal of Humanities and Social Sciences, 3(1), 7-14. https://doi.org/10.24086/cuejhss.v3n1y2019.pp7-14 
Apuke, O. D. (2017). Quantitative Research Methods: A Synopsis Approach. Kuwait Chapter of Arabian Journal of Business and Management Review, 6(11), 40-47. https://doi.org/10.12816/0040336

Bank Indonesia. (2014). Peraturan Bank Indonesia Nomor 16/8/PBI/2014 tentang Perubahan atas Peraturan Bank Indonesia Nomor 11/12/PBI/2009 tentang Uang Elektronik (Electronic Money). Peraturan BI No 16/8/PBI /2014.

Carrión, G. C., Nitzl, C., \& Roldán, J. L. (2017). Mediation analyses in partial least squares structural equation modeling: Guidelines and empirical examples. Partial Least Squares Path Modeling: Basic Concepts, Methodological Issues and Applications, (January), 173-195. https://doi.org/10.1007/978-3319-64069-3_8

Combi, M. (2016). Cultures and Technology: An Analysis of Some of the Changes in ProgressDigital, Global and Local Culture. Cultural Heritage in a Changing World, 1-322. https://doi.org/10.1007/978-3-319-29544-2

Deloite. (2014). Digital Transaction Banking Opportunities \& Challenges.

Gia-Shie Liu, \& Pham Tan Tai. (2016). A Study of Factors Affecting the Intention to Use Mobile Payment Services in Vietnam. Economics World, 4(6), 249-273. https://doi.org/10.17265/23287144/2016.06.001

Group, T. I. (2018). Key Trends in Digital Payments Markets and Strategic Infrastructure.

Hartl, E., \& Hess, T. (2017). The role of cultural values for digital transformation: Insights from a delphi study. AMCIS 2017 - America's Conference on Information Systems: A Tradition of Innovation, 2017-Augus(August).

Khaniwale, M. (2015). Consumer buying behavior. International Tourism, 14(2), 278-280. https://doi.org/10.4324/9780080941288-25

Lin, W.-R., Wang, Y.-H., \& Hung, Y.-M. (2020). Analyzing the factors influencing adoption intention of internet banking: Applying DEMATEL-ANP-SEM approach. https://doi.org/10.1371/journal.pone.0227852

Moqbel, M., Guduru, R., \& Harun, A. (2020). Testing mediation via indirect effects in PLS-SEM : A social networking site illustration. Data Analysis Perspectives Journal, 1(October), 1-6.

Nilekani, S. N., Khan, S. H. R., Sansi, S. K., Sharma, S. A., \& Jain, S. S. (2019). Report Of The High Level Committe on Deepening of Digital Payment. Mumbai.

Putra, Y. S. (2016). THEORITICAL REVIEW : TEORI PERBEDAAN GENERASI. Among Makarti, Vol.9 No.1(1952), 123-134.

Saragih, S. P., \& Nopriadi, N. (2019). Pengaruh Budaya Terhadap Actual Use Digital Payment System Pada Pelaku UMKM di Kota Batam. Journal of Applied Informatics and Computing, 3(2), 63-67. https://doi.org/10.30871/jaic.v3i2.1646

Sipayo. (2017). Karakter 4 Generasi, Baby Boomer, X, Y, dan Z dalam Dunia Pekerjaan. Retrieved March 2, 2021, from sipayo.com website: https://www.sipayo.com/2017/05/karakter-4-generasi-babyboomer-x-y-dan-z-dalam-dunia-pekerjaan.html

Stevens, A. (2019). Managing the CX Demands of 5 Generations | ABA Banking Journal. Retrieved February 23, 2021, from ABA Bank Marketing website: https://bankingjournal.aba.com/2019/11/managing-the-cx-demands-of-5-generations/

Swain, B., Kumar, A., Dhir, S. S., \& Devadutta, K. (2020). A Comparative Study between Digital Transactions and Cash Transactions: An Analytical Study. 29(11), 2257-2262. 
RSF Conference Series: Business, Management and Social Sciences, Vol. 1 (3), 1-8

Generation X Consumption Behavior Model in Using Digital Transactions

Afni Sirait, Ida Ayu Purnama

Victor, V., Thoppan, J. J., Nathan, R. J., \& Maria, F. F. (2018). Factors influencing consumer behavior and prospective purchase decisions in a dynamic pricing environment-an exploratory factor analysis approach. Social Sciences, 7(9). https://doi.org/10.3390/socsci7090153 